\title{
Advances in the Management of Upper Gastrointestinal Subepithelial Tumor: Pathologic Diagnosis Using Endoscopy without Endoscopic Ultrasound-Guided Biopsy
}

\author{
Hang Lak Lee \\ Department of Internal Medicine, Hanyang University Seoul Hospital, Hanyang University College of Medicine, Seoul, Korea
}

Until now, biopsy methods for subepithelial tumors (SETs) have focused on endoscopic ultrasound (EUS)-guided biopsy; however, these methods have several limitations. We devised a simple method for pathologic diagnosis of SETs. SETs are occasionally diagnosed during endoscopy, and lesions are generally small and asymptomatic. It can be challenging to decide on a management plan for large asymptomatic SETs. EUS imaging provides information regarding the size, layer, and echo pattern of the lesions. Patient management plans have traditionally been determined based on EUS images, whereby the endoscopist chooses to either monitor or remove the tumor. However, EUS alone cannot diagnose and evaluate upper gastrointestinal SETs with high accuracy. As sufficient tissue samples are required for the accurate diagnosis of SETs, EUS-guided biopsy techniques such as EUS fine-needle aspiration and trucut biopsy are currently used. However, these methods have a relatively low diagnostic accuracy and do not always provide information upon immunohistochemical staining. Endoscopists can easily detect a submucosal mass after creating an iatrogenic mucosal ulcer, after which tissue sampling is performed by using endoscopic biopsy. Furthermore, pathologic results can differentiate between benign and premalignant lesions. Here, we introduce a simple method for the pathologic diagnosis of SETs. Clin Endosc 2016;49:216-219

Key Words: Subepithelial tumor; Diagnosis; Endoscopy

\section{INTRODUCTION}

Subepithelial tumors (SETs) are often detected during diagnostic endoscopy. ${ }^{1}$ Most SETs are asymptomatic and many such lesions are clinically unimportant. However, SETs can have malignant potency and it is therefore critical to be able to exclude malignant or premalignant lesions. ${ }^{2}$

Among SETs, the malignant potential of gastrointestinal stromal tumors (GISTs) is related to size; however, malignancy

Received: April 26, 2016 Revised: May 19, 2016

Accepted: May 19, 2016

Correspondence: Hang Lak Lee

Division of Gastroenterology, Department of Internal Medicine, Hanyang University Seoul Hospital, Hanyang University College of Medicine, 222-1 Wangsimni-ro, Seongdong-gu, Seoul 04763, Korea

Tel: +82-2-2290-8354, Fax: +82-2-2298-9183, E-mail: alwayshang@hanyang.ac.kr

(c) This is an Open Access article distributed under the terms of the Creative Commons Attribution Non-Commercial License (http://creativecommons.org/ licenses/by-nc/3.0) which permits unrestricted non-commercial use, distribution, and reproduction in any medium, provided the original work is properly cited. can be detected in smaller lesions. ${ }^{3}$ While endoscopic ultrasound (EUS) is often used diagnostically, the accuracy of EUS imaging alone is not sufficient. When used in combination with EUS-guided fine-needle aspiration (FNA), diagnostic accuracy increases although diagnostic yields vary by study. ${ }^{4}$ Thus, linear-type EUS should be used for biopsy, despite this procedure's limitations in cases of small SETs. We have previously performed endoscopic biopsy using an endoscopic submucosal dissection (ESD) technique in SETs. ${ }^{5}$ In this review, we discuss the role of endoscopic biopsy in the pathologic diagnosis of SETs.

\section{THE LIMITATIONS OF EUS FINDINGS AND EUS-GUIDED BIOPSY IN THE DIAGNOSIS OF SET}

EUS enables evaluation of mass characteristics such as size, 
layer, delineation, and echogenicity. ${ }^{6,7}$ Management plans for SETs are determined by algorithm using EUS findings. With this algorithm, endoscopists decide on either regular monitoring or surgical resection of the tumor. ${ }^{8}$ However, EUS imaging alone is not sufficiently accurate for diagnosing SETs $^{9}$ and large tissue samples are required to increase the accuracy of pathologic diagnosis. ${ }^{10}$ For this reason, EUS-guided mass biopsies such as EUS-FNA and trucut biopsies (EUS-TCBs) are currently used. However, EUS-FNA has a relatively low diagnostic accuracy of just $62 \%$ and does not consistently provide information upon immunohistochemical staining. ${ }^{11,12}$ While EUS-TCB does overcome some of the limitations of EUS-FNA, it too has a diagnostic accuracy of less than $60 \%$. Linear-type EUS and EUS-FNA needles are required for EUS-guided biopsy; however, this technique has some limitations in cases of small SETs. Jumbo forceps biopsies and biteon-bite techniques are generally not able to provide sufficient tissue samples. ${ }^{13}$

\section{ROLE OF SIMPLE ENDOSCOPY IN THE DIAGNOSIS AND MANAGEMENT OF SET}

\section{Deep biopsy procedure}

Endoscopic biopsies of SETs were performed using a flex knife, IT2-knife, and a standard upper endoscope by a single, expert endoscopist. An epinephrine solution in hypertonic saline was injected into the submucosa, after which an approximately $0.6-\mathrm{cm}$ incision was made using a flex knife. The IT2-knife was introduced through this site and an incision approximately $15 \mathrm{~mm}$ in diameter was made in the overlying mucosa. Next, minimal submucosal dissection was performed using the flex or IT2-kinife. After subepithelial mass detection, multiple biopsies were performed where a subepithelial lesion was detected beneath the submucosal layer. After the procedure, the iatrogenic incision was closed by clipping (Fig. 1).

\section{Clinical features of upper GI SETs and deep biopsy results}

A total of 52 patients who underwent EUS for upper gas-
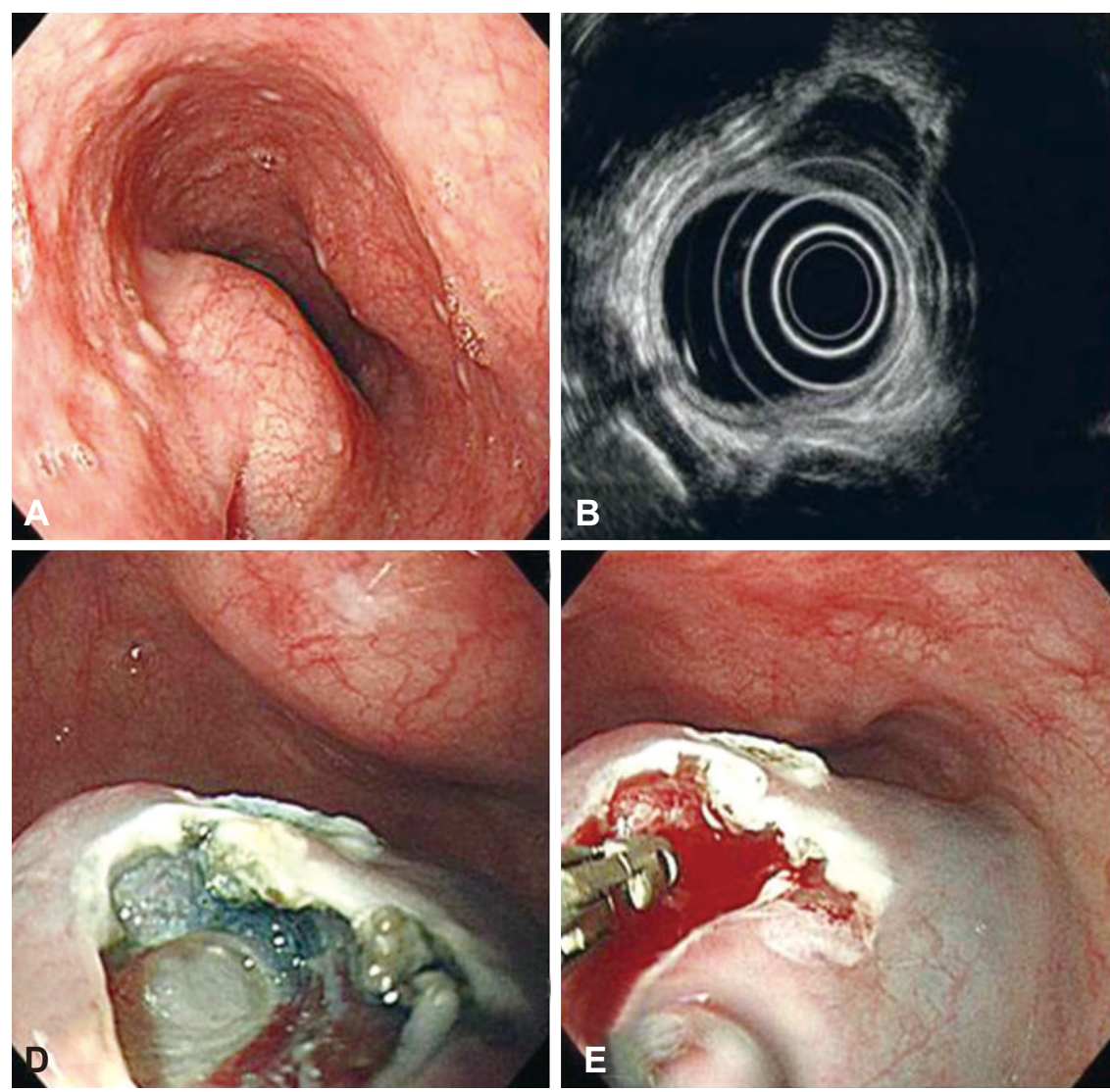

Fig. 1. Deep biopsy technique. (A) The esophageal subepithelial tumor. (B) Endoscopic ultrasound finding showed a hypoechoic mass on proper muscle layer. (C) Submucosal injection. (D) About $10 \mathrm{~mm}$ hole was made using a knife. (E) Through the dissected area, multiple endoscopic biopies were performed using biopsy forceps. (F) Clips were applied to the incision site to close and secure the area. 
trointestinal tract SET were pathologically diagnosed using a deep biopsy technique. Patients were included based on EUS examination and a lesion size $>2 \mathrm{~cm}$ in diameter. Lesions were well-circumscribed masses originating in the muscularis propria or submucosal layer of the stomach.

Endoscopic histologic diagnosis of SETs was made after the ESD technique was performed. Of these patients, the mean age was $52.03 \pm 13.35$ years and 22 were male. The mean diameter of the SETs was $24.15 \pm 6.0 \mathrm{~mm}$ and the diagnostic yield was $96.15 \%$. Of the 52 SETs, 45 were located in the stomach, four in the esophagus, and three in the duodenum. Their pathologic diagnoses were as follows: 17 leiomyomas, 13 GISTs, 11 ectopic pancreases, two carcinomas, two inflammatory fibroid polyps, two Brunner's gland hyperplasias, two lipomas, and one glomus tumor; with two cases that remained undiagnosed. Cases were classified as benign or malignant and just 16 cases were found to be malignant or malignant-related lesions. The mean procedure time was $13.44 \pm 2.41$ minutes. There were three complications associated with this procedure. In the esophageal SET patient, a pneumomediastium developed after the procedure; however, the patient's condition improved with conservative treatment. The glomus tumor patient exhibited major active bleeding during the procedure and endoscopic hemostasis was performed without issue. One patient presented with hematemesis 2 days after the procedure. A work-up revealed minimal bleeding at the procedure site that stopped naturally without further endoscopic hemostasis. Surgical resection was performed in eight cases and all other patients are undergoing regular follow-ups.

\section{Prospective study comparing the endoscopy and surgery groups}

We performed a prospective study to investigate the effectiveness of pathologic diagnosis of SETs. A total 68 patients with SETs in the upper gastrointestinal tract were assigned to one of two groups. The first group (40 patients) underwent EUS and endoscopic deep biopsy using the ESD technique and the second group (28 patients) underwent surgical resection after EUS without pathologic confirmation, in accordance with management algorithms. The results of deep biopsy caused a change to the treatment plans in 14 of 40 patients (35\%). One patient with lymphoepithelial carcinoma was scheduled for surgical resection and 13 patients with benign SETs of diameters $\geq 2 \mathrm{~cm}$ avoided surgery. Of the 28 patients who underwent surgical resection without pathologic confirmation, 12 (42.9\%) were confirmed to have benign SETs. ${ }^{14}$ Our research suggests that deep biopsy is a safe, highyield diagnostic method in patients with SETs. Pathologic diagnosis could improve clinical decision making in the management of patients with SETs and avoid unnecessary surgical resection.

\section{CONCLUSIONS}

Deep biopsy technique is a safe diagnostic method of high diagnostic yield when compared with EUS-guided biopsy for confirming the histopathologic diagnosis of SETs. Sufficient tissue sampling is possible using this method regardless of SET location and linear-type EUS is not required. In cases of SET, pathologic confirmation is more important than findings by EUS, as pathologic confirmation improves clinical decision making for the management of SETs. This diagnostic method should be considered for SETs before determining whether tumors should undergo long-term monitoring or surgical resection.

\section{Conflicts of Interest}

The author has no financial conflicts of interest.

\section{REFERENCES}

1. Hedenbro JL, Ekelund M, Wetterberg P. Endoscopic diagnosis of submucosal gastric lesions. The results after routine endoscopy. Surg Endosc 1991;5:20-23.

2. Park YS, Park SW, Kim TI, et al. Endoscopic enucleation of upper-GI submucosal tumors by using an insulated-tip electrosurgical knife. Gastrointest Endosc 2004;59:409-415.

3. Silberhumer GR, Hufschmid M, Wrba F, et al. Surgery for gastrointestinal stromal tumors of the stomach. J Gastrointest Surg 2009;13:12131219.

4. Philipper M, Hollerbach S, Gabbert HE, et al. Prospective comparison of endoscopic ultrasound-guided fine-needle aspiration and surgical histology in upper gastrointestinal submucosal tumors. Endoscopy 2010;42:300-305.

5. Lee HL, Kwon OW, Lee KN, et al. Endoscopic histologic diagnosis of gastric GI submucosal tumors via the endoscopic submucosal dissection technique. Gastrointest Endosc 2011;74:693-695.

6. Rösch T. Endoscopic ultrasonography in upper gastrointestinal submucosal tumors: a literature review. Gastrointest Endosc Clin N Am 1995;5:609-614.

7. Caletti G, Deviere J, Fockens P, et al. Guidelines of the European Society of Gastrointestinal Endoscopy (ESGE) Part II: retroperitoneum and large bowel, training. The European Endosonography Club Working Party. Endoscopy 1996;28:626-628.

8. Hwang JH, Rulyak SD, Kimmey MB; American Gastroenterological Association Institute. American Gastroenterological Association Institute technical review on the management of gastric subepithelial masses. Gastroenterology 2006;130:2217-2228.

9. Hwang JH, Saunders MD, Rulyak SJ, Shaw S, Nietsch H, Kimmey MB. A prospective study comparing endoscopy and EUS in the evaluation of GI subepithelial masses. Gastrointest Endosc 2005;62:202-208.

10. Eckardt AJ, Wassef W. Diagnosis of subepithelial tumors in the GI tract. Endoscopy, EUS, and histology: bronze, silver, and gold standard? Gastrointest Endosc 2005;62:209-212.

11. Hoda KM, Rodriguez SA, Faigel DO. EUS-guided sampling of suspected GI stromal tumors. Gastrointest Endosc 2009;69:1218-1223.

12. Fernández-Esparrach $\mathrm{G}$, Sendino $\mathrm{O}$, Solé $\mathrm{M}$, et al. Endoscopic ultra- 
sound-guided fine-needle aspiration and trucut biopsy in the diagnosis of gastric stromal tumors: a randomized crossover study. Endoscopy 2010;42:292-299.

13. Cantor MJ, Davila RE, Faigel DO. Yield of tissue sampling for subepithelial lesions evaluated by EUS: a comparison between forceps biopsies and endoscopic submucosal resection. Gastrointest Endosc 2006;64:29-34.

14. Tae HJ, Lee HL, Lee KN, et al. Deep biopsy via endoscopic submucosal dissection in upper gastrointestinal subepithelial tumors: a prospective study. Endoscopy 2014;46:845-850. 